\title{
Reflections on life in the time of the Coronavirus pandemic, from the viewpoint of two people who have experienced dialysis and kidney transplantation
}

\author{
Rossella Picillo ${ }^{1}$ - Alina Seman ${ }^{1}$ \\ Published online: 13 April 2020 \\ (c) Italian Society of Nephrology 2020
}

A as in amicizia, the Italian word for friendship.

For 15 years we have supported each other, helped and understood each other. Actually, over the years, we have understood that nobody really understands us.

It was just me and her, and she and me. Family, companions, friends, our doctors, our nurses, our colleagues understand us up to a point, some better, others not at all.

One can fully understand what life with chronic kidney illness is like only when one has personally experienced long years of dialysis, transplantation, surgery for the arteriovenous fistula, fistula clotting, countless vascular hematomas, worrying about potassium, phosphorus and calcium levels, thirst, not being able to drink, endless lists of forbidden food, sleepless nights caused by restless legs, itching etc.

We have experienced all this while continuing to work, going to the gym, shopping, cultivating friendships, even love, cooking and doing the laundry, traveling and going to the movies. Living and enjoying life. Because life must be lived, not suffered, not survived. Surviving is not enough, we care about living. And we want to live well.

Rossella Picillo and Alina Seman have equally contributed to this paper.

Editor's comment Two old friends, whose friendship started almost 15 years ago in a dialysis ward, have shared their feelings about their lives in the time of the Coronavirus pandemic. Their experience of dialysis and kidney transplantation can help us to better understand the feelings of our patients, and their message will support health care workers at a time when hope is so much needed.

Rossella Picillo

rossella.picillo@gmail.com

Alina Seman

seman_alina@yahoo.com

1 Turin, Italy
And we learned to do this thanks to our "Chronic Patient Alter Ego", who taught us to give the right weight/value to things, experiences, needs, people. To everything.

We have many facets and roles, like everyone does.... You do as I do and I do just like you. Like her-I am a woman, daughter, sister, partner, aunt, friend, expert on my work, art lover, music lover, fan of training in the gym. And yes, I am also a patient. A chronic patient.

One of us was lucky enough to be transplanted for the second time in December 2018. Endless joy. New life. The other continues to be on dialysis four times a week. Both of us feel fine. We are both immunosuppressed and fragile, but we are fine. Today, in March 2020, in the time of the COVID-19 pandemic, we are facing a new danger. Our most valuable asset, health, is even more at risk than before. That's right, our most precious asset. Now more than ever, the world is learning in the worst way possible what really matters, what is worth protecting and fighting for.

Total lockdown. But not for me.

\#istayathome only Wednesdays, Fridays and Sundays.

Isolation does not apply on Mondays, Tuesdays, Thursdays and on Saturday mornings, when I have to leave the house to go to the hospital. A 4-h dialysis session. Mask, gloves, gel, rigid protocol leaving and returning home. I no longer take the elevator. Both my apartment and the dialysis ward are on the 4th floor. Excellent, more exercise. I don't touch anything. I don't talk to anyone. I pass the checkpoints in front of the hospital 'I have to go to the dialysis ward'. 'No symptoms?'. 'Right, I'm fine'. And $4 \mathrm{~h}$ later, returning, the same scene.

Luckily, I work for a company that accepts and promotes working from home. Nothing new for me there. My company approved agile work for the first time in 2015, 2 days a week; now 5 days a week at home are also fine. I have to 
say that more work gets done at home, and the day passes quickly.

Then, I practice yoga online twice a week, I read, I watch Netflix, Amazon Prime, TIM Vision and now we also have the Disney channel.

Quarantine's 40 days are not enough for me to see the many films and series produced worldwide. Getting bored? Absolutely not. I would also like to learn to play the piano. I've found a very good app. There is an app for everything these days. Complain? What for? In times of a global health crisis like this? Absolutely not.

Resilience is my middle name.

There are many other difficult things, tough situations, hard choices, heavy decisions, suffering. Many others. I got sick in 2005; I was 27-year-old. I have had 6 years of dialysis and a kidney transplant that lasted almost 10 years. I've undergone various operations, made dozens of specialist visits, dozens of instrumental examinations. And in 15 years I have taken more than 40,000 pills of all types, sizes and colors.

Do I have to stay indoors? OK no problem.

What have I been doing? Respecting the rules, applying hygiene and social distancing protocols, relying on hospital staff, relying on trustworthy sources of information. I enjoy my house, my partner, the traffic-free streets around my house. I don't think much about the risk of exposure. I want to be serene. I'm doing my part and I trust that others will do theirs. Anxiety and worries are enemies in this period. And they don't bring anything good.

$\mathrm{R}$ as in resilience, $\mathrm{R}$ as in Rossella.

Resilience is my second name.

My first name begins with $\mathrm{R}$ like resilience does.

I'm immuno depressed because for 20 years (since I was 30) I have suffered from chronic kidney disease, and altogether have been on dialysis for 12 years and received two kidney transplants. Now I'm fine, even now during the COVID-19 pandemic.

I've been through it all and my minute and consumed body has experienced breast cancer diagnosed in time, pancreatitis and the inevitable heart problem, heart failure caused by dialysis. Ah yes, because I was, I am and I'm going continue to be an athlete. I have not given up on sports; even now, I work out assiduously, daily, in my 70-square-m apartment. And I've never stopped working. I am a much appreciated human resource manager for a large French multinational company and I am very proud of myself.

Illness teaches us how to be in the world, and how to give value to what is really important in life: affections, love, respect for health, care for small things, nature, art in all its expressions.
I've been in quarantine since mid-February. I isolated myself long before the emergency measures were put in place by the whole community. Many other people laughed at me and looked scornfully at me and my mask- the policemen in the police station where I had gone to collect my passport, post office clerks, my colleagues.

An unpleasant episode happened when I brought together my relatives scattered around the globe (American and English aunts, uncles and cousins) in a Facebook group and provided testimony and advice on how they should protect themselves from the Coronavirus. The response was terror and disbelief, which made most of them leave the group without so much as a thank you or how are you? What a disappointment.

You need to be resilient in times like this. How? Doing only what you like, reading, painting, writing, studying cooking, enjoying tidying up and so on.

What a gluttonous opportunity this Coronavirus has provided. A moment of imposed stop, a useful moment for all of you to reflect as deeply and intimately as you can. You, who have never experienced disease, will come out better in the end, and perhaps you will have the tools to understand that those seen as being the weakest often are STRONG WARRIORS. Perhaps thanks to COVID you will acquire empathy, civic sense and emotional intelligence.

Perhaps thanks to COVID the whole world will change, nature and man will be put at the center, and capitalism with its consumerism, ephemeral hedonism, its power and financial games, its uselessness revealed through brazen social posts by bloggers and self-styled influencers, bound to an unreal and glossy image... perhaps in the wake of death and dismay, a better world will rise, a truly new globalized society.

Those who never experienced disease, will probably finally understand Schopenhauer's aphorism "Health is not everything, but without health everything is nothing".

Be resilient!

You are only being asked to stay at home. For those who cannot stay home, I wish a good new resistance in the trenches. We will come out stronger and better, believe me.

From my window I see the sun shining even if it is cloudy. Life is beautiful (Fig. 1).

We both also want to underline some positive aspects of our future "life after COVID"...

We will hopefully have more respect for our national health system. And for research. We'll see an end to crazy cuts in staff and funding in this sector. Without health, we stop living. And life is precious. The air we breathe will have more value, we will find a way not to win the title of the most polluted city in Europe and we will appreciate our freedom, and the happiness of having a normal life, with its routines and little everyday things - having a job, going 


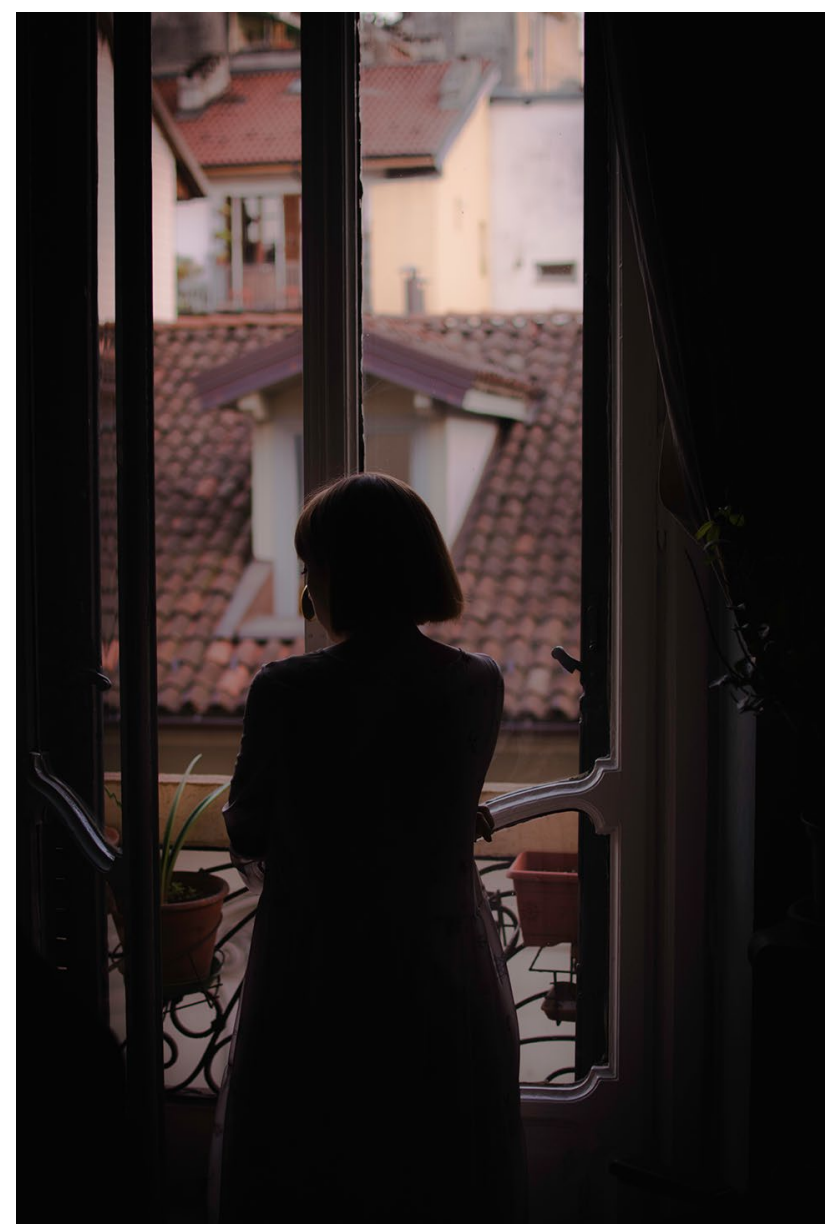

Fig. 1 From my window, hommage to Andre Kertesz; courtesy of Edoardo Terzolo. Note: "From my window" is the title of a late book of photographs by Andre Kertesz, variations on the theme of small objects in front of the same window; the title and the melancholia of the original photographs were felt in line with the present situation of confinement to the gym, doing the shopping, going for an aperitif with friends and taking a run in our favorite park.

And then of course there's travel, going to the sea and to the mountains, even just for a weekend. What joy!

In short, everything will have another flavor. But my friend and I have understood this for a long time. From this point of view, we are ahead of others. We didn't need COVID to get to this awareness.

What we can say, being chronically ill, having spent years battling illness, facing the risks to our lives, constant vulnerability, is that this situation indeed raises the state of alarm, but that we are able to cope with this and continue to live, to work, to cook, to do the laundry, etc. And without complaining. Holy Resilience. And what we wholeheartedly hope is that a vaccine will soon be found, by researchers in Italy or elsewhere in the world, because if healthy people can leave their houses soon, we will need to take more care, because we really are at risk, and we care about life.

$$
\text { And you? }
$$

Funding No funding was received for this editorial.

\section{Compliance with ethical standards}

\section{Conflict of interest No conflict of interest to declare.}

Publisher's Note Springer Nature remains neutral with regard to jurisdictional claims in published maps and institutional affiliations. 